\title{
TOEFL iBT Speaking, Goal - orientation and self-assessment a study of Iranian EFL learners
}

\author{
Forough BARZGARN, Dr. Hamed GHAEMI
}

\begin{abstract}
M.A.in TEFL, Department of English, Neyshabur branch, Islamic Azad University, Neyshabur, Iran foroughbarzgaran@yahoo.com
\end{abstract}

Assistant professor of ELT, Department of TEFL, Neyshabour Branch, Islamic Azad University,

Neyshabur, Iran; Hamedghaemi@gmail.com

\begin{abstract}
Owing to the growing attention to learner's independence and autonomy, self-assessment has received considerable attention in recent years. Nevertheless, this notion is not well-known to most English language teachers and students in Iran where traditional assessment is still dominant. This study explored the effect of self-assessment on EFL learners' TOEFL iBT speaking score, goal orientation as well as scrutinizing the relationship between Iranian EFL learners' goal-orientation and their speaking scores in TOEFL iBT test. To do so, 72 advanced EFL learners who were both male and female studying in Jahan Elm institute of higher education in Mashhad, Iran participated in the current study. Experimental group consisted of 36 EFL learners while control group encompassed 36 EFL learners. All participants took TOEFL iBT test, goal orientation questionnaire during the first and final week of the semester (i.e. pretest, posttest) and being trained through the TOEFL iBT software. Independent sample $t$ test and Pearson correlation coefficient were used to find the difference between the two groups in terms of their speaking scores and goal orientated behavior and to find the relationship between goal orientation and speaking score of TOEFL iBT test. Results from the two post measurements indicated that students in the experimental group showed statistically significant gains on speaking scores and their goal orientated behavior as compared with the control group. Moreover, outcomes illustrated the existence of significant positive correlation between the learning goal orientation and TOEFL iBT speaking scores of EFL learners. In sum, the results of this study suggest that self-assessment should be integrated into regular TOEFL iBT preparation courses in order to help TOEFL iBT candidates become independent learners and ultimately achieve more satisfactory results in English proficiency tests, particularly TOEFL iBT test.
\end{abstract}

Keywords: TOEFL iBT, Speaking test, Speaking Proficiency, self-assessment, goal-orientation.

\section{Introduction}

An essential requirement of a learning process is learners' awareness of their abilities, their weaknesses, their progress, and their skills. Regarding leading role of assessment, Anderson (1998) suggests that assessment influences what is taught and learned in the classroom. As Farhady (2003) proposes, "It has become a tradition in the Iranian educational system in general and language related majors in particular to implement traditional testing systems for the evaluation of the students' achievement" (p.1). Educators have become more and more vocal in calling for alternatives to traditional student assessment practices. Anderson (1998) further states that abandoning traditional assessment and using alternative assessment has been demanded. Thus, in order to compensate for the deficiencies of traditional assessment, alternative assessment has fascinated the attention of scholars (Chen, 2008). 
Alternative assessment comprises performance assessment, portfolio assessment, students' self-assessment, peer-assessment and so forth (Huerta-Macias, 1995). In this sense, training learners in the skill of self-assessment has been highly recommended by Harris (1997). Self-assessment, which can be understood as measurement supported by learners themselves, can play an important role in helping learners to observe their learning progress or to evaluate their language proficiency. Through involving learners in the assessment process, they learn the merits needed for good performance, how assess their own performance or achievement, how to set personal goals, and finally they develop the habit of self-reflection (Rolheiser and Ross, 1998).

The logical outcome of increased attention in learner-centered language teaching and selfdirected language learning is regarded as self- or peer-assessment by Birjandi and Hadidi (2012). Research on language pedagogy mentions that teachers should provide opportunities for students to assess their language level so as to help them focus on their own learning (Blanche, 1988; Blue, 1994; Dickinson, 1987; Harris, 1997; Henner-Stanchina \& Holec, 1985; Oscarsson, 1989). Despite the importance of self-assessment, learners are rarely placed in charge of rating their own performance (Luoma \& Tarnanen, 2003). Within this situation, as Taras (2001) argued, teachers are sending out the wrong message to students. Teachers lead leaners to believe that the main focus of interest is the score. Teachers' correction of their students' paper results in some question symbols and some ticks. Once students submit their work they typically become disengaged with the assessment process. Hence, opportunities for learning are missed as they become passive recipient of assessment outcomes.

Oscarson (1989) considers self-assessment as an integral element of learners' formulating goals. From a general point of view, self-assessment and goal-oriented learning have a main influence on learners' academic achievement. Self-assessment by Oscarson (1989) considers as a fundamental element of learners' formulating goals. Butler and Lee (2010) added that through self-assessment learners increase their awareness of goals and expectations consequently they are able to monitor their learning progress, and evaluate their level of knowledge against the goals and criteria decided by the curriculum. Oscarson (1989) further elaborate on goal orientation as one of the benefits of using self-assessment in the language classroom.

The idea of goal orientation which was offered by Dweck and Elliot (1983) came about to define unpredictability in natural goal preferences that a person implicitly arranges for him/herself to accomplish a task. Language learners can be learning or mastery oriented or performance oriented. Learning orientation is seen as the desire to gain first-hand, detailed knowledge of a given task or matter, and performance orientation is the aspiration to display a person's capability on a definite matter or assignment. (Button, Mathieu, \& Zajac, 1996). Moreover, people with learning goal orientation are more inclined to look for feedback but people with performance approach orientation will only look for feedback if they understand that the feedback will be positive and fruitful (Payne, Youngcourt, \& Beaubien, 2007). This results in highlighting the role of assessment in the process of learning.

Goal orientation theory (also referred to as Achievement Goal Theory) states that students have different orientations toward certain types of goals (Was, 2006). Mastery and performance orientations are the dominant theoretical approach to goal orientation. The simple difference between these goal orientations contends that students who set mastery goals focus on learning the materials and mastering the tasks at hand (Was, 2006).

It is worth mentioning that Brdar et al. (2006) introduces adoption of different types of goals by students in the educational system as one of the significant concepts in motivational research. Indeed, the goals that students adopt will have an effect on their success and failure. Therefore, all goals are not established to approach a desirable outcome; that is, good grades. They can also be adopted towards avoiding an undesirable consequence; that is, being grounded for failure (Elliot, 2005). In fact, the reasons that students' motivation differs from each other, have to do with their goal orientations. Moreover, students' adoption of different types of goals dependent 
on different factors such as classroom procedures, practices, and the like (Ames, 1992, cited in Beghetto, 2004). In this regard, self-assessment as a classroom procedure or practice can highly affect students' choices of goals.

The popular conducted researches on goal orientation theory which is on the increase, has brought about different interpretations and conceptualizations of central concepts and research methods (Elliot, 2005; Hulleman, Schrager, Bodmann, \& Harackiewicz, 2010). The primary researchers had examined motivation and self-regulated learning (e.g., Dweck, 1986, 1992; Nicholls, 1984) consequently identified two broad achievement goal orientations: performance goals and mastery goals. Performance goals (i.e., ability or ego goals) refer to an individuals' inclination for representing skills and ability. The main concern of Individuals who pursue performance goals might outperforming others rather than simply representing their own abilities. Generally, mastery goals associations are having a focus on a task for the sake of learning, civilizing g competence and understanding, acquiring new knowledge and skills. On the other hand, performance goals associations are having a focus on a task for the sake of outperforming or besting others, displaying ability, superiority and competence and avoiding portrayal of lack of ability or competence. Mastery orientation is self-referential and the standards of achievement are set by the individual while the standards of accomplishment in performance orientation are relative to others (Schunk, Pintrich, \& Meece, 2008).

Adding to the distinction between performance goals and mastery goals, more current conceptualizations of goal orientation theory have made a distinction between the components of mastery and performance goals (e.g., Elliot, 1999; Elliot \& McGregor, 2001). Achievement goals can be further divided to approach or avoidance forms, outcome of such a division is a $2 \times 2$ framework. This framework comprises four achievement goal orientations: performance-approach, mastery-approach, performance-avoidance, and mastery-avoidance (Was 2006).

Additionally, the role of goal-orientation in language learning is also substantial in that it influences the way students view the task and engage in it. Thus, it is very important to determine the students' underlying goals in performing different activities (Pintrich \&Schunk, 2002). Kwokwai (2002) thinks of achievement goal orientation as one of the main determinants of students' motivation and achievement. Accordingly, goal theorists have stated that motivation is supposed to be conceptualized as goal-directed behaviors that are presented by learners in an achievement environment (Ames, 1992).

Pintrich and Schunk (2002) define motivation from the cognitive point of view in which goals play very significant roles in leading individuals toward or against an achievement. An increasing number of Iranians learn English as a Foreign Language (EFL) and since the first introduction of Test of English as a Foreign Language internet-based Test (TOEFL iBT) in September 2005, there has been a growth in the number of Iranian language learners who take TOEFL iBT tests and associated preparation courses. While it seems that the motivations for learning English and taking the TOEFL iBT by Iranian learners are varied, ranging from personal language acquisition to professional goals including enhancing the possibilities of overseas study and meeting tertiary graduate requirements, little research exists to confirm factors that may influence their goals in learning TOEFL iBT. Thus, this can overemphasize investigation of Iranian TOEFL iBT candidates' goal orientations.

Oscarson and Apelgren (2011) consider dual purposes for self-assessment including estimation of results as well as promotion of learning. Thus, they conclude that a reorientation of assessment is required. Previous studies have showed that self-assessment can be a reliable learnerdirected measure of English proficiency that brings test-takers' voices to the validation of learning process (LeBlanc \& Painchaud, 1985; Ross, 1998). Self-assessment has also been used as a supplementary tool to existing assessment projects, as the European Language Portfolio (ELP) project (Alderson, 2005; Engelhardt \& Pfingsthorn, 2013; Hellekjær, 2009; Lee \& Greene, 2007). 
This study examines how reliably international students' performance on the TOEFL iBT has been determined by their goal oriented thoughts. To this end, as Manganello (2011) argues if examinees have the necessary combination of knowledge, careful evaluation, and clear goals for language acquisition they stand the best chances of performing well on tests of English proficiency such as TOEFL iBT. The key issue at hand is that self-assessment may be one of the most accessible instruments that can easily reach out to most of the targeting participants with a uniform set of items, compared with teacher evaluation. (Zhi, 2015). Furthermore, strength of the statistical relationship between examines ' goal orientations which according to literature would be affected by applying self-assessment task in preparation courses.

\subsection{Statement of the problem}

Despite the fact that goal orientation has been conceived to result from self- assessment, little work has been done in this field (Baleghizadeh \& Masoun, 2014). Moreover, it is further investigated by Baleghizadeh (2014) that increased goal-orientation is reported to be related to the effort and perseverance toward performing a task until it is accomplished. Hence, a richer understanding of the role of self-assessment in students' awareness of their own strengths and weaknesses. In line with this issue, applying self-assessment task may cause an improved performance in TOEFL iBT. So, while self-assessment has been promoted in various educational contexts, very little empirical examination has been under-taken of its instructional effectiveness in foreign language learning, especially international exam era. One may also deduce that the implementation of self-assessment can be challenging if the learning context, like the learning context of Iran, has traditionally been focused on teacher-centered instruction and measurementdriven assessments, or if the environment is characterized by a high degree of competitiveness among students. Hence; the present study aims to improve the understanding of learners' selfassessment by examining the effectiveness of self-assessment in TOEFL iBT speaking domain in Iranian candidates with different goal orientations as a case study.

Harris (1997) in stating the benefits of self-assessment notes that self-assessment theory, increasing learner's knowledge of their learning goals and their learning needs, enhances their motivation and consequently their goal orientations. Also, it is claimed that one of the reasons to integrate self-assessment in to language course is that it increases motivation and goal orientation in learning. The result of several of the reviewed studies also established that self-assessment practices in the field of languages has increased students motivation (Blanche \& Merino, 1989).

Furthermore, the inconsistent findings of research on self-assessment highlight the need for more research. A similar plea was also voiced by some scholars (e.g. Brantmeier, 2006; Oscarson, 1997; Ross, 1998), acknowledging the scarcity of research in the area of self-assessment in foreign language context. So, in this study, self-assessment and goal-orientation are contextualized within the domain of TOEFL iBT specifically the self-assessment and goal-orientation in speaking performance of TOEFL iBT candidates.

An exploration of students' ability to assess their own proficiency in a second language context is substantial because the process requires students to explore critically what they are capable and incapable of doing. This evaluative process also requires an individual to be honest with him/herself and to assess within a frame of reference that is of relevance to them. From a pedagogical perspective self-assessment can provide teachers with useful information which will allow them to have a better global understanding of the students perception of the level at which they are performing as well as to provide the teacher with a more flexible measures of determining the needs and abilities of the students.

This study is worthy to be carried out because little research has been done before in Iran to investigate self-assessment learning and goal-oriented learners in foreign language learning. The investigation of achievement goal-orientation and self-assessment in Iran would be efficient to 
respond the question that why some TOEFL iBT candidates with the same instruction may attain higher proficiency than others. Finally, it is through this research that one may be able to determine the role of self-assessment in TOEFL iBT preparation courses.

Goal-oriented learning has become an important issue in educational psychology because of their influence on learners' achievement. Lemose (1999) believes that self-assessment involves the individual's capacity to organize behavior according to one's purposes (goals). It also involves the self-management of the various regulatory processes, triggered and connected by goal settings (p.471). According to this study, learners illustrate different levels of engagement and involvement in their learning activities because of their different purposes and goals which lead them to act differently.

If the results of the study indicate a positive effect of self-assessment on learners' performance may prove that their ability and their goal-oriented behavior can enhance overtime, then it will shed some light on the importance and value of this technique in improving students' performance in international examination specifically speaking performance. Thus, learners, teachers, policy makers, test developers and material developers will benefit the results. It will also open up the doors of introducing new trends in assessment to teachers and learners.

\subsection{Research questions and hypotheses}

This study is going to answer the following questions:

Q1: Does applying self-assessment tasks have any statistically significant effect on speaking performance of Iranian TOEFL iBT candidates?

Q2: Does applying self-assessment tasks have any statistically significant effect on Iranian TOEFL iBT candidates' goal orientation?

Q3: Is there any significant relationship between goal-orientation and speaking performance of Iranian TOEFL iBT candidates?

Based on the above-mentioned questions, the following null hypotheses were developed:

HO 1: self-assessment does not have any statistically significant effect on speaking performance of TOEFL iBT candidates?

H0 2: applying self-assessment tasks does not have any statistically significant effect on Iranian TOEFL iBT candidates' goal orientation.

H0 3: There is not any significant relationship between goal-orientation and speaking performance of Iranian TOEFL iBT candidates.

\section{Method}

\subsection{Participants}

The participants in the present study were a group of TOEFL iBT candidates who were getting ready to participate in TOEFL iBT test. The participants were selected through administering placement test of Hafez Mashhad English institute. They were from different geographic regions of Iran, representing Persian as their first language. They were aged between 26 and 40.The majority of the participants were taking TOEFL iBT preparatory course to seek higher education or to earn a degree after completion of the University or for a more professional Goals such as improving probability of studying abroad. They randomly assigned to an experimental $(n=36)$ and a control $(n=36)$ group. While the participants in both experimental and control groups received the goal-orientation questionnaire and TOEFL iBT speaking test as pretests and posttests. Only the participants in the experimental group received a biweekly self-assessment task.

\subsection{Instruments}


In this study, three different instruments were employed:

\subsection{Self-assessment task}

A self-assessment task was adapted from Blanche and Merino (1989) (see Appendix A); in this task, students were asked to identify classroom topics (whether grammatical, functional, or lexical) they considered important, the main difficulties they thought they had while learning the topics, and strategies they believed can help to overcome these difficulties. This instrument allowed students to focus on their assets as well as their shortcomings and made students reflect on all the various aspects of the course (Blanche \& Merino, 1989).This self-assessment task included 10 items that students should have answered, covering different aspects of the course. The first section asked for details about the topics the students found important in the past lessons, requires them to rate how important they believed each topic was, and how well they believed they can learn the topic. A 5-item scale ranging from not at all to thoroughly/extremely be used for ratings.

In the next section, students were tested to transcribe the vocabulary they have learned since the last self-assessment and then were asked to rate how important they believed each word was. A5-item scale was utilized for these ratings. In the third section, students were asked to rate their general evaluation of their gained learning using a 5-descriptor scale ranging from learning nothing at all through $a$ lot in the last two weeks. In the last section, students were asked to describe their weaknesses and the changes they would have made to their study habits. Additionally, they were expected to give their suggestions about the focus of instruction during the following selfassessment period.

\subsection{Goal-orientation questionnaire}

A goal orientation developed by Was (2006) was utilized. The English version of the questionnaire consisted of 34 items, each six items measuring a different goal orientation, namely mastery goal orientation, performance approach goal orientation and performance avoidant goal orientation, and work avoidant goal orientation. A five-point Likert scale, ranging from 1 (not at all true of me) to 5 (completely true of me), was used to rate each item. By providing the sum of the scores for each construct by the number of items related to that part, the total score for each construct was calculated. The reliability of the Persian version of the Goal Orientation Scale was tested using Cronbach alpha, which was found to be .64 to .81. Thus, the Persian version of the Goal Orientation Scale enjoyed a satisfactory reliability index. Validity of the questionnaire were checked by Was (2006).

\subsection{TOEFL iBT software (TPO-TOEFL Practice Online and Longman)}

The Speaking section of TOEFL iBT consisted of six tasks. Two are independent tasks, which required examinees to express opinions on familiar topics. The other four are integrated tasks. Two of the four are Listening/Speaking tasks, which required examinees to listen to a short spoken text and then respond to it. The remaining two are Reading/Listening/Speaking tasks, which required examinees to read a short text, listen to a spoken text that pertained to the reading text, and then respond about what they had read and heard. For each task, examinees are given 15-30 seconds to prepare, and 45-60 seconds to respond. Each examinee's response to each task is scored on a scale of $0-4$ by trained raters. Each speaking response of those students who completed Form A only is scored by a single rater, and the score given by the rater is the final score for that task. Each speaking response of a subsample of students who completed both Forms A and B is rated by two raters. When there are discrepancies of more than one point, a chief rater provided the final score for the task. The raw Speaking section score is a sum of the points earned on the six tasks. TOEFL iBT speaking test's reliability estimated by ETS is .86. 


\subsection{Procedure}

The following procedure was followed while collecting the data.

As the first step, the institution's placement test was administered to measure the participants' English language proficiency and to make sure that both control and experimental groups were homogeneous. Then the participants in both groups were exposed to the same instruction, as they were learning English in the same institute. The system of instruction was homogenized based on communicative language teaching. The learners were taught by the same teacher based on the same syllabus and received the same training through TOEFL iBT software (TPO-TOEFL Practice Online and Longman). Thus, it can be claimed that both groups were in the same condition. The only difference between the two groups was that the students in the experimental group received self-assessment training.

In the first phase, after investigating candidates' TOEFL iBT speaking scores the goal orientation questionnaire was completed by the participants in both groups in the first session of the classes. Students in the experimental group were given instructions on self-assessment task in the first session. The self-assessment tasks, however, were completed by the participants in the experimental group on a bi-weekly basis throughout the term (for four weeks). The participants were also allowed to ask questions whenever they faced any problem while filling in the selfassessment tasks.

In this study, self-assessment was practiced as a tool to monitor students' performance. The self-assessment instrument consisted of items where learners situate themselves in a language task and then evaluate their own performances. The participants were introduced to self-assessment for the first time. The aim was to familiarize them with self-assessment through explanation of related issues such as organization, content, and grammar. Examples were given to explain how they could deal with the content of the tasks. Moreover, the participants were asked to self-assess for about 3035 minutes at the end of each unit. They were also told that they were not going to receive any score. After four weeks students felt they could follow the instruction in how to self-evaluate their progress using the task. Consequently, they showed improvement in self-correction. It is found that these four weeks of the term were quite efficient for teaching students how to work with the tasks.

For both groups, the goal orientation questionnaire was completed and handed in during the final week of classes for the second time. Once all posttest questionnaires were collected and coded, the researchers keyed in the data for analysis. Additionally, their scores in TOEFL iBT speaking was considered while collecting the data in posttest.

\subsection{The design of the study}

In the present study each classroom was considered an intact group, given that it was difficult to divide each classroom to randomly assign each student to an experimental or control group. Thus, a quasi-experimental study was conducted. As random selection is not possible because the experimental study was done in a classroom setting, a quasi-experimental pre-test/post-test control group design was adopted. This design helped the researcher to investigate the effect of selfassessment as the independent variable on speaking performance of TOEFL iBT candidates as dependent variable. The same design was conducted to examine the effect goal orientation on selfassessment of the TOEFL iBT speaking scores. In order to measure the degree of relationship between students' goal orientation and their speaking performance in TOEFL iBT an expo facto study was designed.

\section{Data analysis}

Creswell (2007) defines data analysis as the process of making sense out of the data. The data of the study were analyzed by following Data analysis included the following stages: 
First, the treatment was withheld from the control group. In this case, the self-assessment component was administered to willing participants in the treatment group. That is, the selfassessment component was introduced at the beginning of the semester in the experimental group and completion of the self-assessment questionnaire did not impact the students' grades in any way, so the students did not feel compelled to raise or lower their scores to please the instructor or to improve their final grade.

Second, faulty randomization procedures were avoided by choosing an approximately equal number of classes participating in both the treatment and control groups. It was estimated that the groups would self-regulate because there might be some students dropping out of the course in the first weeks of the semester, both in the treatment and control groups.

\subsection{Sampling}

Since the participants of the study consisted of TOEFL iBT candidates to determine the sample size Cochoran formula was conducted:

$$
n=\frac{\frac{z^{2} p q}{d^{2}}}{1+\frac{1}{N}\left(\frac{z^{2} p q}{d^{2}}-1\right)}
$$

This formula:

$\mathrm{n}=$ sample size

$\mathrm{N}=$ population size

$\mathrm{Z}$ or $\mathrm{t}=$ standard error

$\mathrm{P}=$ proportion of population lacks certain traits

$\mathrm{q}(1-\mathrm{p})=$ proportion of population lacks certain traits

$\mathrm{d}=$ degree of certainty

According to the above formula, the sample size was divided with a population of 0.5 the standard error is estimated to be 1.96. Also, degree of certainty was 0.01 or 0.05 . Consequently, Cochran showed that in a population of 85 candidates the sample size is 70 . To address the effect of the missing or incomplete questionnaires the population was estimated with $10 \%$ increase. Thus, the sample size was 77 candidates which finally 72 questionnaires were received.

\subsection{Reliability of the instrument}

Cronbach alpha coefficient was used to measure the reliability of goal orientation questionnaire. After calculating the score variance and total variance the following formula was used:

$$
r_{\alpha=} \frac{J}{J-1}\left[1-\frac{\sum s_{j}^{2}}{s^{2}}\right]
$$

$\mathrm{J}=$ number of sub-questions in the questionnaire

$S 2 j=$ the subset variance of $j$

$\mathrm{S} 2=$ total variance

The goal orientation questionnaire Cronbach alpha coefficient was calculated .64 to .81 while using SPSS. 


\subsection{Descriptive statistics of variables}

The descriptive statistics for all data including mean, median, standard deviation, skewness, and kurtosis reported in table 1

Table 1: Descriptive Statistics of data

\begin{tabular}{cccc} 
& Goal orientation & Speaking & Self- assessment \\
\hline Number & 72 & 72 & 72 \\
\hline Mean & 3.1964 & 2.9838 & 2.3730 \\
\hline Standard deviation & 0.195 & 0.360 & 0.218 \\
\hline Skewness & 0.269 & 0.185 & -0.037 \\
\hline Kurtosis & 0.109 & -0.697 & -0.768 \\
\hline Minimum & 2.14 & 1.83 & 1.43 \\
\hline Maximum & 4.29 & 4.33 & 3.29
\end{tabular}

As table 1 shows, the mean score for goal orientation was 3.19 and the minimum and maximum scores were respectively 2.14 and 4.29. Also, the degree of skewness and kurtosis of goal orientation was 0.269 and 0.109 . According to table 1 the mean scores for speaking and selfassessment of the sample were 2.98 and 2.37.

\subsection{Normality of distribution}

To investigate normality of distribution, variables were subjected to the application of OneSample Kolomogorov-Smirnov (K-S) tests for each group. This assesses the normality of the distribution of scores for the two groups. The normality of distribution is one of the essential and fundamental assumptions of parametric tests. The results of the application of K-S tests-in this case significance values of variables were more than 0.05 - suggest that the assumption of normality is not violated. (A non-significant result, sig. value of more than .05 , indicates normality.)

Table 2:Test of normality

\begin{tabular}{|c|c|c|c|c|}
\hline & & Speaking & Self-assessment & Goal orientation \\
\hline & $\mathrm{N}$ & 72 & 72 & 72 \\
\hline Mean & \multirow[t]{2}{*}{ Normal Parametersa,b } & 2.9838 & 2.3730 & 2.7956 \\
\hline Std. Deviation & & .60005 & .46650 & .46296 \\
\hline Absolute & \multirow[t]{3}{*}{ Most Extreme Differences } & .099 & .103 & .092 \\
\hline Positive & & .099 & .092 & .088 \\
\hline Negative & & -.083 & -.103 & -.092 \\
\hline \multicolumn{2}{|c|}{ Kolmogorov-Smirnov Z } & .840 & .874 & .780 \\
\hline \multicolumn{2}{|c|}{ Asymp. Sig. (2-tailed) } & .481 & .430 & .578 \\
\hline
\end{tabular}

\subsection{Investigating the research hypothesis}

To investigate the results, the independent sample t test was used to answer the first question:

Does applying self-assessment tasks have any statistically significant effect on speaking performance of Iranian TOEFL iBT candidates?

The assessment of this assumption involves investigating whether self-assessment have any statistically significant effect on speaking performance of TOEFL iBT candidates? 
Table3: Independent sample test

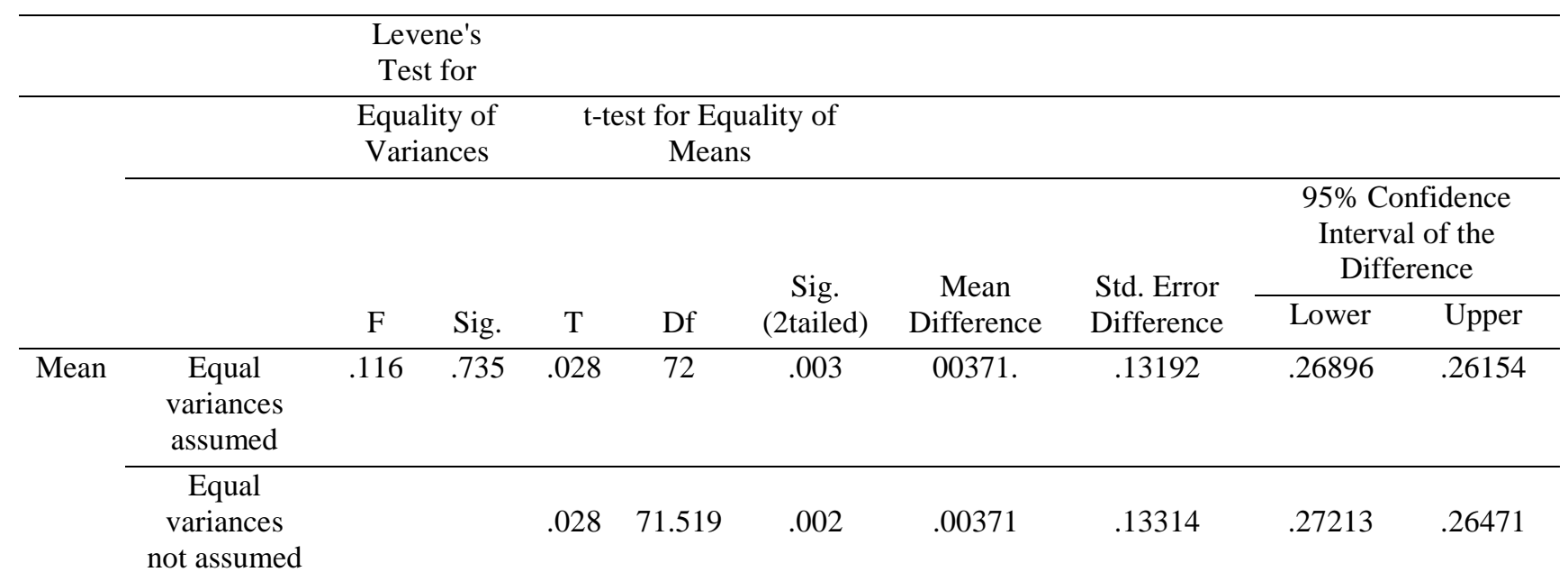

Based on the results of the data in table 3 the null hypothesis that "Self-assessment does not have any statistically significant effect on speaking performance of TOEFL iBT candidates is rejected. Since sig. (2- tailed) is $\mathrm{p}=.003$. This value is less than .05 . That is to say, self-assessment practices helped the participants of the present study to improve their speaking skill as measured with TOEFL iBT test.

\subsection{Second null hypothesis}

The second null hypothesis assuming "applying self-assessment tasks does not have any statistically significant effect on Iranian TOEFL iBT candidates' goal orientation "was tested.

Table 4: Independent sample test

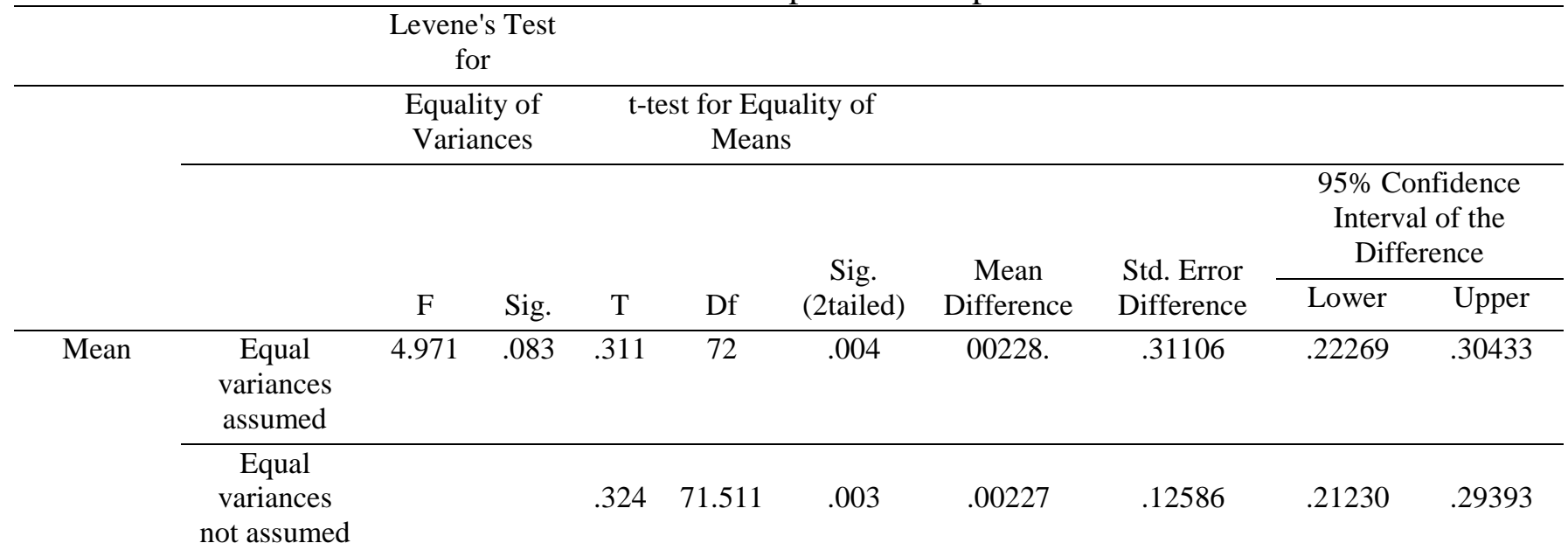

As shown in table 4 the sig. (2-tailed) value is $p=.004$. This value is less than .05 . It can be concluded that there is a statistically difference between the groups in their speaking scores. Therefore, the second null hypothesis which stated that goal orientation does not have any effect on the candidates TOEFL iBT speaking score is rejected. 


\subsection{Third null hypothesis}

In order to investigate the third null hypothesis, there is not any significant relationship between goal-orientation and speaking performance of Iranian TOEFL iBT candidates a Pearson correlation coefficient was used. The result can be observed in tabe5.

Table 5: Correlations

\begin{tabular}{|c|c|c|c|}
\hline & & Speaking & Goal orientation \\
\hline \multirow{3}{*}{ Goal orientation } & Pearson Correlation & .399 & 1 \\
\hline & Sig. (2-tailed) & .003 & \\
\hline & $\mathrm{N}$ & 72 & 72 \\
\hline
\end{tabular}

In the third question the relationship between goal orientation and TOEFL iBT speaking was under investigation. This led the researcher to correlate these two variables based on the gathered data which ended in a significant positive relationship between the two variables at $p$ - value $=003$ and confidence level of $97 \%$ ( table5). Pearson correlation coefficient for this test is 0.399

Table 6: Correlations between TOEFL iBT speaking scores and components of goal orientation

\begin{tabular}{lr} 
Mastery goals & .41 \\
\hline Performance goals & .29 \\
\hline Performance avoidant & .28 \\
\hline Work avoidant & .12
\end{tabular}

Table 6 shows that the mastery goal orientation positively related to TOEFL iBT speaking score (0.41).performance goal orientation positively related to TOEFL iBT speaking score as well (0.29). And the performance-avoid goal orientation positively related to TOEFL iBT speaking score (0.28), and no significant relationship between work avoidant goal orientation (0.12) and TOEFL iBT speaking score.

\section{Discussion}

On balance, the research evidence recommends that self-assessment contributes to higher student achievement and improved behavior (Ross, 2006: 5). The issue most often focused on in the literature is the accuracy of self-assessments. But in this study and particularly in the first research question, an endeavor was made to find out the effect of self-assessment on a particular skill i.e. speaking. The language learners in this study who were taught to do self-assessment were likely to have better speaking skill. As this study indicated that teaching students self-assessment seemed to help develop student monitoring and regulating of their learning of speaking. Students were gradually able to self-track areas of strength and weakness and set some clear goals for improvement. These results might be due to the effect of active learning on students' understanding and achievement.

The regular employment of the self-assessment tasks in class as well as outside the class had great effects on studentse ${ }^{\text {ee }}$ sense of autonomy in their speaking skill. As the few first sessions passed, the students in the experimental group who were once unwillingly using the tasks to monitor their improvement, started implementing the tasks eagerly.

The result of independent sample $t$ test for comparing the two groups in the present research also indicated a significant difference between experimental and control groups in terms of improving their speaking score. Actually, the experimental group outperformed the control group in terms of their score of speaking in TOEFL iBT. It can be concluded that their scores have 
developed because self-assessment personalized the evaluation process and the students were doing it themselves with no external evaluation. Their improvement in scores may be due to the fact that they had become more conscious of the kinds of things they had learned in class. It made them feel good about their speaking skills. In addition, it showed them where their strengths were and where they could improve. In this respect, one could assume that the tasks could have a positive "wash back' effect on the students' speaking score in TOEFL iBT.

Outcomes indicated to self-assessment as a recognition of educational assessment offers many educational advantages such as stimulating self-monitoring in learners, giving ongoing feedback, increasing self-esteem and motivation of learners and teachers, evaluating via clear standards, highlighting mastery and progress, and mostly bringing about positive washback effect. In addition to Gipps (1994) study there are other studies which proved this finding of present study. For instance McNamara (2001) and Bailey (1999) emphasized in their finding of study that self assessment boosts learner autonomy, and learner autonomy can lead to positive washback.

These results are in line with the theoretical and empirical studies that contribute to the worth of self-assessment in language teaching. The outcomes add to the findings of previous studies (Butler \& Lee, 2010; de Saint Léger, 2009). De Saint Léger (2009) claims that as a consequence of self-assessment, self-perception develops positively over time in relation to fluency, vocabulary, and self-confidence in speaking in L2 which is confirmed by the findings of the present study. Her study highlighted the potential pedagogical advantages of self-assessment at both cognitive and affective levels. The findings of Butler and Lee (2010), who establish that learners' ability to selfassess their performance improved over time as they come to conclude that self-assessment bring about a positive but peripheral effect on English learners' performance and confidence

In the self-assessment tasks used in this study, students were requested to state the topics they had learned and how much they had learned in relation to each topic covered during instruction. As students restated what and how well they had learned, they were apt to increase the level of enactive mastery experience, often defined as the learner's own performance and direct experience, which is also considered as a contributing factor to improve goal orientation.

Accordingly, Andrade and Du (2007) also looked at students' attitudes toward selfassessment, and found that students reported positive attitudes toward self-assessment after extended practice. Likewise, the attitudes to self-assessment as an alternative measurement approach in EFL in Israel was examined by Smith (1997), who focused on the attitudes of learners to self-assessment compared to teacher and examination grades. Smith recognized that "Pupils in the 12thgrade perceived self-assessment as having greater validity than teacher assessment" (p. 2). Students trusted their own assessments best, claiming they knew more about their language competence even when accepting summative examination results. The students also addressed the risk of overrating their language competence in high-stakes situations. She suggested it as a complementary assessment method.

The second question investigated the effect of using self-assessment on improving TOEFL iBT candidates' goal orientation level. The results reported in Table 4 revealed that the treatment group differed significantly from the control group. In other words, the formative rather than summative practice of self-assessment elements enhanced EFL learners' goal orientation level. The findings merit the discussion of previous studies. For example, the obtained results are in line with Baleghizadeh and Masoun (2014) who considered the effect of self-assessment on students' boosted goal orientation in an EFL context. The finding also support Blanche and Merino (1989) claim that enhanced awareness of the learning process and improved goal orientation as the advantage of self-assessment over teacher-centered assessment. However, the present study goes beyond the findings of previous research by exploring the effect of self-assessment on TOEFL iBT speaking scores' boosted goal orientation in an EFL context.

The third question aimed at examining the relationship between goal orientations and speaking scores of TOEFL iBT candidates reveled that those language learners who are goal- 
oriented are more successful at language proficiency as well. The results are in accordance to Dehgan (2007) study. Roebken (2007) in his study found that goal-oriented learners with both mastery and performance goals reported to have more satisfaction with their academic experience and showed higher academic achievement.

In a similar vein, Tercanlioglu and Demiroz (2015) investigated the relationship between goal orientation and reading strategy of Turkish students. Results revealed that mastery oriented students seem to make use of more strategies in L1 and L2 may be drawn. They are more strategic than the other participants. They are more persistent to fulfill the reading tasks. Therefore, the mastery goal oriented participants put more cognitive effort, and they do this consciously.

The research also aimed to determine the extent to which TOEFL iBT speaking scores were related to components of goal orientation. To shed light on this issue, a correlational analysis was conducted between TOEFL iBT speaking scores and scores on each of the components of goal orientation. One consistent finding of this study was that mastery approach goals compared to performance approach, performance avoidance, and work avoidant goals, relate most favorably to speaking score of TOEFL iBT across different achievement goal standards. The beneficial effects of mastery approach goals in this study are in line with earlier analysis on trait goal orientation (Payne et al., 2007) and state goal orientation (Rawsthorne \& Elliot, 1999; Utman, 1997), referring to the positive effects of mastery approach goals.

The evidence that refers to the negative impact of performance-avoidance goals, including anxiety, self-handicapping strategies, lack of persistence, and poor performance (Kaplan \& Maehr, 2007; Senko, Durik, \& Harackiewicz, 2008). Research on the relationship between achievement goals and performance however, has not generated identical results. Performance goals in some cases have been investigated to end in better performance than mastery goals (e.g., Pintrich 2000), while in other cases mastery goals have been found to produce a better performance (e.g., Ames, 1992; Ames \& Archer, 1988; Dweck, 1986). In yet other cases, no differences were explored in the effects of mastery and performance goals (e.g., Study 1A \& 1B, Elliot et al., 2005). This variety in findings may be an indicator of point that performance goals were not necessarily as damaging as assumed; instead they showed both negative and positive effects.

Despite the recent emphasis in Iran on standards, and owed to the unfortunate alignment of constructivist approaches and standards, it is very difficult to harmonize formative and summative assessments, as Sluijsmans et al. (1998) pointed out, these alternative forms of assessment should be a part of a process of change towards a student centered learning environment. This change requires a shift in emphasis from the norm-referenced to the criterion-referenced testing, from purely summative to formative and summative assessment, from external to internal evaluation, and from the assessment of product to the assessment of process as well. A combination of the summative aspect use of the process, that teachers' formative work would not be undermined by summative pressures should be applied to gain the most advantages of the process

\section{Conclusion and discussion}

The goal of this study was to investigate the possible effects of self-assessment in TOEFL iBT preparatory courses on EFL learners and their goal orientation. The findings showed that candidates benefit from involvement in the assessment process. The candidates got more learningoriented through applying self-assessment during the course. From the results of the present study, not only it can be concluded that self-assessment is indeed a pedagogically beneficial assessment tool that can improve TOEFL iBT candidates speaking scores, but also candidates' learning goal orientation provided that enough training and practice are regularly offered to them.

Given the importance of goal orientation in language learning, it is significant for language teachers to improve it. Dweck (1986) asserts that the role of contextual factors in implementing goal orientation cannot be ignored. This implies that language teachers specifically TOEFL iBT 
instructors can create classroom environments that encourage learners to adopt one type of goal orientation. Since the result of the study showed that learning goal orientation increased as the result of introducing self-assessment, EFL teachers need to focus on suitable contexts so that students would benefit from the effect of self-assessment on the development of learning goal orientation.

As Claxton and Murrell (as cited in Ho, 1999) emphasize, gaining information about the learners' learning style preferences can assist the teachers to target the areas of strength and to find the areas of weaknesses in the learners, to make the necessary adaptations and changes in the instruction, to proposes strategies in order to expand their learning and, hence, assist the learners to take charge of their own learning and gain self-sufficiency in the learning process. Moreover, the self-assessment practice can help students become aware of and strive for an acceptable level of captivating knowledge that is suitable for the standards which have been specified for the level of mastery intended for each skill and, hence, improve their speaking performance (Sharagard \& Mallahi 2014).

According to the findings of this study in EFL context, language scholars should consider the fact that mastery oriented learners can perform better in language proficiency tests. On the other hand, proving and avoiding performance oriented learners might be less powerful at performing in proficiency tests. The results of this study is somehow supported by Ford and his colleagues (1998) they believe that not only learning oriented learners are superior in cognitive works but also they get more involved in meta-cognitive works (planning, monitoring, and revising behaviors) in the process of learning. However, performance oriented learners showed inferior capability to pass on performance at the end of training and less inclined to favor challenging tests (Ford et. al., 1998).

The appreciated point for teachers to know as referred by Holec (1979), since too often they place value solely on summative evaluation. In this regard, teachers may need to be persuaded that this procedure serves an educational purpose, not only for the students, but for themselves as well in that by agreeing the students the opportunity to participate more actively in their learning so as to develop more opportunity in the acquisition of the second language. Actually, students must be geared to developing their higher order thinking skills so that this reflective process becomes a watching device in their repertoire of metacognitive skills. Implications

The most direct implication of the findings of this study is related to language teaching specifically TOEFL iBT instructors. Given the positive findings of the present study, language teachers are strongly recommended to include comprehensive self-assessment in their teaching practice. They can integrate various kinds of self-assessment practice (such as the one applied in this study) in their instruction. Teachers can also make use of this strategy as a scaffolding tool. In the other words, they can apply self-assessment means after each unit of work in order to focus the learners' attention on a target issue in the process of instruction.

With the maintenance of the learners' favorable reactions and the positive effect of selfassessment on speaking skill of the candidates, this study concludes that self-assessment is a viable alternative to involve students in the assessment process and serves as a way to diversify the assessment culture in Iran. The findings of the study may have some implications for various groups. Teachers can use the evaluative feedback stemmed from self-assessment to increase their support of learners. Teachers may also find it beneficial to adopt self-assessment as an effective means for development of foreign language learners' speaking skill. Also, by use of self-assessment practices, learners can recognize the specific areas in where they need help and support, and then they can seek help from their teacher. Moreover, since the positive effect of self-assessment on EFL learners speaking skill was found in this study, methods of teaching and material development in language classes can be designed in such a way that encourage self-assessment techniques and consequently affect foreign language learners' language skill.

The results then showed whether a specific goal orientation was more or less useful than another goal orientation. The experiment results does not allow for interpretations about the relationships between each goal orientation and the examined outcome. The implication for 
achievement goal theory from the present study is primarily that TOEFL iBT instructors should promote the adoption of mastery approach goals by creating a work-or learning condition that boosts the development of competence, rather than concentrating on avoiding mistakes.

Finally, the researchers hope the present study will be beneficial to those involved in the domain of language teaching to help students develop techniques for their own learning. Teachers' training sessions that give them the insight to trust the accuracy of learners' self-assessment will be valuable. There is no hesitation to say that these finding are very closely bound up with cultural aspects of the setting. Thus, there is a great need for further studies in other contexts in order to get a better understanding of the real position of goal orientation and self-assessment in the realm of language teaching and learning.

\section{Suggestions for Future Studies}

This study donated to our understanding of EFL learners' experiences and perceptions of participating in self-assessment and the effect of this kind of assessment on speaking skill of TOEFL iBT candidates, their goal orientations. The findings not only help teachers plan for classroom assessment but also generate a number of suggestions for future research. Following are recommendations for further investigation into self-assessment. First, there is a paucity of literature on both general and online/computer assisted self-assessment in ESL/EFL with different applications. With the wide access of Internet and email, online/computer-assisted self- and peer assessment would be very favorable (Topping, 1998); Future researchers could examine numerous aspects of online self-assessment.

Second, in terms of self-assessment, this research did not realize other section of TOEFL iBT. Future studies are recommended to conduct a similar study with other sections of TOEFL iBT like writing, reading and listening.

Third, future research could explore EFL learners' and teachers' insights and approaches that might affect self-assessment. As Falchikov and Boud (1989) recommended, the big question future researchers should ask is not, "Are students able to assess themselves?" but, "What might account for the variation in students' ability to assess their own performance?" (p. 396).

Finally, including qualitative research in this area may prove more efficient at uncovering why goals increases for some candidates and how the process unfolds at different stages during the assessment process. With further research on this highly elusive but important phenomenon, foreign language educators can become better equipped to help students self-assess their strengths and weaknesses, self-appraise how to reach their learning objectives, and increase their learning efficacy.

\section{REFERENCES}

1. Andrade, Heidi \& Du, Ying (2005). Student perspectives on rubric-referenced assessment. Practical Assessment, Research \& Evaluation. A peer-reviewed electronic journal, 10, (3), 111 Retrieved March 5, 2011 from http://pareline.net

2. Ames, C. (1992). Classrooms: Goals, structures, and student motivation. Journal of Educational Psychology, 84, 261-271.

3. Alderson, J. C. (2005). Diagnosing foreign language proficiency: The interface between learning and assessment. London, England: Continuum.

4. Anderson, R. S. (1998). Why talk about different ways to grade? The shift from traditional assessment to alternative assessment. New Directions for Teaching and Learning, 74, 5-16.

5. Bailey, K. M. (1999). Washback in Language Testnig. TOEFL Monograph Series, Ms. 15.Princeton, NJ: Educational Testing Service. 
Bulletin de la Société royale des Sciences de Liège, Vol. 86, special issue, 2017, p. 25 - 42

6. Baleghizadeh, S., Masoun, A. (2014). The effect of self-assessment on EFL learners' goal orientation. Iranian Journal of Applied Linguistics, 17, 25-48.

7. Birjandi, P., \& Hadidi Tamjid, N. (2012). The role of self-, peer and teacher assessment in promoting Iranian EFL learners' writing performance. Assessment \& Evaluation in Higher Education, 37, 513-533.

8. Blanche, P., \& Merino, B. J. (1989). Self-assessment of foreign-language skills: Implications for teachers and researchers. Language Learning, 39, 313-349.

9. Brantmeier, C. (2006). Advanced L2 learners and reading placement: Self-assessment CBT, and subsequent performance. System, 34, 15-35.

10. Brdar, I., Rijavec, M., \& Loncaric, D. (2006). Goal orientations, coping with school failure and school achievement. European Journal of Psychology of Education, 21 (1), 53-70

11. Butler, G. Y., \& Lee, J. (2010). The effects of self-assessment among young learners of English. Language Testing, 27, 5-31.

12. Button, S. B., Mathieu, J.E., \& Zajac, D.M. (1996). Goal orientation in organizational research: A conceptual and empirical foundation. Organizational Behaviour \& Human Decision Processes, 67, 26-48.

13. Chen, Y. M. (2008). Learning to self-assess oral performance in English: A longitudinal case study. Language Teaching Research, 12, 235-262.

14. Creswell, J. W. (2007). Qualitative inquiry \& research design: Choosing among five approaches (2nded.). Thousand Oaks, CA: Sage.

15. Dehghan, M. (2005). The relationship between Iranian EFL learner's goal oriented and selfregulated learning and their language proficiency (Master`s thesis). Tarbiat Modares University, Tehran, Iran

16. Dweck, C.S. (1986). Motivational processes affecting learning. American Psychologist, 41,

a. 1040-1048. doi: 10.1037//0003-066X.41.10.1040.

17. Dweck, C. S., \& Elliott E. S. (1983). Achievement motivation. In P. Mussen, \& E. M. Hetherington (Eds.), Handbook of child psychology (pp. 643-692). New York: Wiley.

18. Elliot, A. J. (1999). Approach and avoidance motivation and achievement goals. Educational

19. Psychologist, 34, 169- 189. doi: 10.1207/s15326985ep3403_3.

20. .Elliot, A. J. (2005). A conceptual history of the achievement goal construct. In A. J. Elliot \& C. S. Dweck (Eds.), Handbook of competence and motivation (pp.52-72). New York: Guilford Press.

21. Falchikov, N., \& Boud, D. (1989). Student self-assessment in higher education: A metaanalysis. Review of Educational Research, 59, 330-395.

22. Farhady, H. (2003). Classroom Assessment: A Plea for Change. Paper presented at the 2nd conference on issues in English language teaching in Iran, Tehran, Iran. Retrieved July 3rd, 2011, from http://65.54.113.26/Publication/6146097/classroom-assessment-a-.plea-for-change

23. Ford, J. K., Smith, E. M., Weissbein, D. A., Gully, S. M., \& Salas, E. (1998). Relationships of goal orientation, metacognitive activity, and practice strategies with learning outcomes and transfer. Journal of Applied Psychology, 83, 218-233.

24. Gipps, C. (1994). Beyond testing: Toward a theory of educational assessment. London and New York. Rutledge.

25. Harris, M. (1997). Self-assessment of language learning in formal settings. ELT journal, 51/1:12-20.

26. Huerta-Macias, A. (1995). Alternative assessment: Response to commonly asked questions. TESOL Journal, 5, 8-11.

27. Kaplan, A., \& Maehr, M. L. (2007). The contributions and prospects of goal orientation theory. Educational Psychology Review, 19, 91-110. 
Bulletin de la Société royale des Sciences de Liège, Vol. 86, special issue, 2017, p. 25 - 42

28. Kwok-wai, CH., Po-yin, L., Man-tak, L. \& Phillip, M. (2002). Hong Kong preservice teachers' achievement goal orientations - are they related to their gender and electives? Hong Kong Teachers' Centre Journal, 1, 20-31.

29. LeBlanc, R., \& Painchaud, G. (1985). Self-assessment as a second language placement instrument. TESOL Quarterly, 19(4), 673-687.

30. Lemos, M.S. (1999). Studenta' goals and self-regulation in the classroom. International

a. Journal of Educational Research, 31, 471-485.

31. Luoma, S., \& Tarnanen, M. (2003). Creating a self-rating instrument for second language writing: From idea to implementation. Language Testing, 20, 440- 465.

32. Mangalleno, M. (2011). Correlations in the new TOEFL era: an investigation of the statistical relationships between iBT scores, placement test performance, and academic success of international students at Iowa State University. Graduate Theses and Dissertations. Paper 10219

33. McNamara, T. (1996). Language testing. Oxford, Oxford University Press

34. Oscarson, M. (1989). Self-assessment of language proficiency: Rationale and applications. Language Testing, 6, 1-13.

35. Oscarson, M., \& Apelgren, B. M. (2011). Mapping language teachers' conceptions of student assessment procedures in relation to grading: A two-stage empirical inquiry. System, 39, 2-16.

36. Payne, S. C., Youngcourt, S. S., \& Beaubien, J. M. (2007). A meta-analysis examination of the goal orientation nomological net. Journal of Applied Psychology, 92, 128-150.

37. Pintrich, P. R. (2000). Multiple goals, multiple pathways: the role of goal orientation in learning and achievement. Journal of Educational Psychology, 92, 544-555.

38. Pintrich, P. R., \& Schunk, D. H. (2002). Motivation in education: theory, research, and applications (2nd ed.). Upper Saddle River, New Jersey: Prentice-Hall.

39. Rawsthorne, L.J., \& Elliot, A.J. (1999). Achievement goals and intrinsic motivation: A metaanalytic review. Personality and Social Psychology Review, 3, 326-344. doi: 10.1207/s15327957pspr0304_3.

40. Roebken, H. (2007). The influence of goal-orientation on student's satisfaction, academic engagement and achievement. Electronic Journal of Research in Educational Psychology, 5,679-704.

41. Rolheiser, C., \& Ross, J. A. (1998). Student self-evaluation: What research says and what practice shows. Center for development and learning. Retrieved December, 2011, from http://www.cdl.org/

42. Ross, S. (2006). The reliability, validity, and utility of self-assessment. Practical Assessment, Research \& Evaluation, 11 (10), 1-13.

43. Schunk, D. H., Pintrich, P. R., \& Meece, J. L. (2008). Motivation in education: Theory, research, and applications (3rded.). Upper Saddle River, NJ: Prentice-Hall.

44. Sharagard, R., Mallahi, O., (2014). Relationship between Iranian EFL Learners' Language Learning Styles, Writing Proficiency and Self-assessment. Procedia- Social and Behavioral Sciences, 98, 1611-1620.

45. Sluijsmans, D., Dochy, F., \& Moerkerke, G. (1998). Creating a learning environment by using self-, peer- and co-assessment. Learning Environments Research, 1 (3), 293- 319

46. Smith, A. F. (2000). Reflective portfolios: Preschool possibilities. Childhood Education, 204 208. www.sciencedirect.com Page .

47. Taras, M. (2001). The use of tutor feedback and student self-assessment in summative assessment tasks: toward transparency for students and for tutors. Assessment and Evaluation in Higher Education 26, 605-614.

48. Tercanlioglu, L. \& Demiröz, H. (2015). Goal Orientation and Reading Strategy Use of Turkish Students of an English Language Teaching Department. The Qualitative Report. 20(3), 286-313. 
Bulletin de la Société royale des Sciences de Liège, Vol. 86, special issue, 2017, p. 25 - 42

49. Topping, K. 1998, Peer Assessment Between Students in Colleges and Universities, Review of Educational Research, 68, 3, 249-276

50. Was, C. (2006). Academic achievement goal orientation: taking another look. Electronic Journal of Research in Educational Psychology, 4(3), 529-550.

51. Zhi, L., (2015). Using an English self-assessment tool to validate an English Placement Test.

52. Papers in Language Testing and Assessment. 4(1). Retrieved February, 2016, from http://www.altaanz.org/uploads/5/9/0/8/5908292/li.pdf 